\title{
Genetic Separation of Purine Transport from Phosphoribosyltransferase Activity in Salmonella typhimurium
}

\author{
By CHARLES E. BENSON, ${ }^{1,2}$ DAVID L. HORNICK ${ }^{1}$ \\ AND JOSEPH S. GOTS ${ }^{1 *}$ \\ ${ }^{1}$ Department of Microbiology, School of Medicine and ${ }^{2}$ Department of Medical Technology, \\ School of Allied Medical Professions, University of Pennsylvania, Philadelphia, \\ Pennsylvania, 19104, U.S.A.
}

(Received 1 April 1980)

\begin{abstract}
Two mutants of Salmonella typhimurium were isolated which differ from their respective parental strains in their growth responses to guanine and xanthine. Both mutants had purine phosphoribosyltransferase activities similar to their parental strains. One mutant, CB-3, had a lower guanine uptake rate apparently caused by a genetic lesion in a specific gene (designated guaP) responsible for facilitating the transport of guanine. This gene mapped at $3.5 \mathrm{~min}$ in the sequence azi-guaP-nadC. The second mutant, GP103, had a purine carrier molecule with altered specificity, as demonstrated by a competition between hypoxanthine and xanthine for uptake.
\end{abstract}

\section{INTRODUCTION}

The transport of exogenous purine bases into microbial cells has been described as a group translocation mediated by membrane-bound phosphoribosyltransferases (PRTs) (Berlin \& Oliver, 1975; Hochstadt-Ozer \& Stadtman, 1971 $a$; Jackman \& Hochstadt, 1976) during which each base is converted to its corresponding ribonucleotide by 5-phosphoribosyl transfer from 5-phosphoribosyl-1-pyrophosphate. Evidence supporting this conclusion includes the observation that variations in substrates and inhibitors produced similar effects on transport and PRT activity (Zylka \& Plagemann, 1975), and that the loss of a PRT activity was always followed by specific defects in purine uptake (HochstadtOzer \& Stadtman, $1971 a, b)$.

Several reports (Pickering \& Woods, 1972; Roy-Burman \& Visser, 1975; Thakar \& Kalle, 1968) suggest that purine transport, defined as the movement of bases across the membrane, is a function separate from phosphoribosylation. There are differences between the transport $K_{\mathrm{m}}$ for a specific purine base and the $K_{\mathrm{m}}$ of the corresponding PRT (Thakar \& Kalle, 1968). Dissimilarities in the effects of various inhibitors on transport and PRT activity have also been noted (Berlin, 1970; Berlin \& Oliver, 1975; Roy-Burman \& Visser, 1975; Thakar \& Kalle, 1968). Furthermore, transport-deficient mutants with normal PRT activity have been isolated (Roy-Burman \& Visser, 1975; Thakar \& Kalle, 1968), and in mammalian cells PRT-deficient (or KCN-treated) cells have been shown to accumulate labelled purines under appropriate conditions (Alford \& Barnes, 1976; Zylka \& Plagemann, 1975). Such results imply that an additional component, distinct from the PRTs, may be involved in the transport process.

This paper describes the isolation and characterization of two Salmonella typhimurium strains with defects in purine uptake that are functionally and genetically distinct from the activity of the corresponding PRTs. 


\section{Table 1. Bacterial strains used}

\begin{tabular}{|c|c|c|}
\hline \multirow{2}{*}{\multicolumn{2}{|c|}{$\begin{array}{l}\text { Strain } \\
\text { Salmonella typhimurium }\end{array}$}} & \multirow[t]{2}{*}{ Source/reference } \\
\hline & & \\
\hline LT-2 & Wild-type & M. Demerec \\
\hline $\mathrm{AB} 47$ & $\Delta($ proAB47-gpt $)$ & M. Demerec \\
\hline SL751 & proA46 purC7 purI509 ilvA405 strA rha461 & B. Stocker \\
\hline CB-3 & as SL 751 , but guaP & This paper \\
\hline TM445 & as SL751, but aroP505 hpt guaC & Chou \& Martin (1972) \\
\hline GP103 & as TM445, but with Xar phenotype & This paper \\
\hline PM553 & $\Delta($ proAB47-gpt $)$ leu-798 fol-101 & P. Margolin \\
\hline SM16 & $\Delta(\operatorname{aroP}-a c e B-\operatorname{rad} C)$ & Langley \& Guest (1974) \\
\hline Pan5 & pan-5 & Langley \& Guest (1974) \\
\hline 0002 & aziA gal hisA metA $\mathrm{nml}$ rha trpB & Langley \& Guest (1974) \\
\hline KP4065 & pur $A$ deo $D$ add & J. Hoffmeyer \\
\hline JF12 & as SL751, but nadC19 & Foster \& Moat (1978) \\
\hline SA464 & HfrK1-2 (O-purE...cysE) cw; serA13 rfa-3058 & Sanderson et al. (1972) \\
\hline SA955 & HfrK20 (O-purE. . gal) ccw; serA13 rfa-3058 & Sanderson et al. (1972) \\
\hline \multicolumn{3}{|c|}{ Escherichia coli $\dagger$} \\
\hline $\mathrm{H} \Delta 10$ & $\Delta($ nadC-aroP-ace $)$ & Langley \& Guest (1977) \\
\hline $\mathrm{K} \Delta \mathbf{1 7}$ & $\Delta($ nadC-aroP-ace $)$ & Langley \& Guest (1977) \\
\hline $\mathrm{K} \Delta 22$ & $\Delta($ nad $C$-aroP-ace $)$ & Langley \& Guest (1977) \\
\hline $\mathrm{K} \Delta 27$ & $\Delta($ nad $C-$ aroP $)$ & Langley \& Guest (1977) \\
\hline $\mathrm{H} \Delta 3$ & $\Delta($ nad $C-$ aroP $)$ & Langley \& Guest (1977) \\
\hline
\end{tabular}

* Gene symbols and abbreviations are described by Sanderson \& Hartman (1978).

† Strains described by Langley \& Guest $(1977,1978)$. H parent: Hfr; thi-1 azi-7 relA1. K parent: $\mathrm{F}^{-}$; met $B$ relA1 thy A56 tsx-87 pps azi.

\section{METHODS}

Bacterial strains. The strains used in this study were all derivatives of Salmonella typhimurium LT-2 or Escherichia coli K-12 (Table 1). Transductions were performed as plate crosses using $0 \cdot 1 \mathrm{ml}$ of P22 transducing phage and $0.1 \mathrm{ml}$ of a washed recipient broth culture. Preparation of P22 transducing phage lysates and their assay followed standard procedures (Ely et al., 1974). Conjugation with Hfr or episomecarrying strains was achieved by plate crosses or by concentrating donor and recipient strains to a pellet and interrupting the mating by vigorous vortex and pipette agitation. P1 transduction of Escherichia coli strains was performed according to the technique of Rosner (1972).

Media and culture techniques. The minimal salts medium (ME) of Vogel \& Bonner (1956) was used with glucose $(0.2 \%)$ as the carbon source. When necessary, amino acid requirements were satisfied with either $40 \mu \mathrm{g} \mathrm{ml}^{-1}$ of the appropriate amino acid or $0.1 \%$ (w/v) casein hydrolysate. Purine supplements were $20 \mu \mathrm{g}$ $\mathrm{ml}^{-1}$ unless otherwise indicated. Quantitative growth responses were monitored in liquid media with a KlettSummerson photocolorimeter using the green filter (no. 54). Tube cultures $(5.0 \mathrm{ml})$ were aerated on a roller drum apparatus and large broth cultures $(100$ or $200 \mathrm{ml})$ were incubated overnight in 11 culture flasks on a rotary shaker water-bath (New Brunswick). All cultures were incubated at $37^{\circ} \mathrm{C}$.

Chemicals. The tetrasodium salt of 5-phosphoribosyl-1-pyrophosphate was purchased from Sigma. $\left[8-{ }^{14} \mathrm{C}\right]$ Hypoxanthine $\left(48.6 \mathrm{mCi} \mathrm{mmol}^{-1}, 1.798 \mathrm{GBq} \mathrm{mmol}^{-1}\right),\left[8-{ }^{14} \mathrm{C}\right]$ adenine $\left(53.5 \mathrm{mCi} \mathrm{mmol}{ }^{-1}, 1.980 \mathrm{GBq}\right.$ mmol $\left.{ }^{-1}\right)$, $\left[8-{ }^{14} \mathrm{C}\right]$ guanine $\left(5.41 \mathrm{mCi} \mathrm{mmol}^{-1}, 200 \cdot 2 \mathrm{MBq} \mathrm{mmol}^{-1}\right)$ and $\left[8-^{-14} \mathrm{C}\right]$ guanosine $\left(49 \cdot 2 \mathrm{mCi} \mathrm{mmol}{ }^{-1}\right.$, $\left.1.820 \mathrm{GBq} \mathrm{mmol}^{-1}\right)$ were obtained from New England Nuclear. $\left[2{ }^{14} \mathrm{C}\right]$ Xanthine $\left(48 \mathrm{mCi} \mathrm{mmol}{ }^{-1}, 1 \cdot 78 \mathrm{GBq}\right.$ $\mathrm{mmol}^{-1}$ ) was purchased from Schwarz Mann. The scintillation fluid used in the Packard Tri-Carb scintillation counter was Omnifluor (New England Nuclear) dissolved in toluene (Baker, analytical grade). $N$-Methyl$N^{\prime}$-nitro- $N$-nitrosoguanidine (NG) was obtained from Sigma.

Extracts and enzyme assays. Cultures were grown in 100 to $200 \mathrm{ml} \mathrm{ME}$ with appropriate supplements. Cell-free extracts were prepared and assayed for purine phosphoribosyltransferases and GMP reductase as described previously (Benson et al., 1971; Gots et al., 1972). Protein concentrations were determined by the Lowry method with bovine serum albumin as the standard.

In vitro competition with guanine-xanthine phosphoribosyltransferase $(G P R T)$. The conversion of a ${ }^{14} \mathrm{C}$ labelled purine (hypoxanthine or xanthine) to its ribonucleotide form was measured in the absence and presence of an unlabelled competing purine. The concentration of the labelled purine was $50 \mathrm{nmol}$ per $0.5 \mathrm{ml}$ reaction mixture in a series of 12 tubes, while the concentration of the competing purine ranged from 2 to $100 \mathrm{nmol}$ per $0.5 \mathrm{ml}$ reaction mixture. The mixture was incubated at $37^{\circ} \mathrm{C}$ for 5 min and then the 
reaction was terminated by placing the entire set of tubes in a boiling water bath for 2 min. The amount of nucleotide formed during incubation was established by thin-layer chromatography as described previously (Gots et al., 1972).

Uptake of labelled purines. Overnight cultures were diluted 1:5 in ME medium supplemented with the appropriate purine base and amino acids and were grown for $1.5 \mathrm{~h}$ at $37^{\circ} \mathrm{C}$. Cultures were harvested by centrifugation and diluted in ME medium without glucose to an absorbance of 0.25 at $540 \mathrm{~nm}$ on a Zeiss spectrophotometer (equivalent to $60 \mu \mathrm{g}$ dry wt $\mathrm{ml}^{-1}$ ). Diluted cells were starved by stationary incubation at $37^{\circ} \mathrm{C}$ for $1.5 \mathrm{~h}$. At this time, $0.2 \%$ glucose and the appropriate ${ }^{14} \mathrm{C}$-labelled purine base or nucleoside $\left(0.05 \mu \mathrm{mol} \mathrm{ml}^{-1}, 0.05 \mu \mathrm{Ci} \mathrm{ml}^{-1}\right)$ were added and $1 \mathrm{ml}$ samples were collected every $20 \mathrm{~s}$ for 2 min on mernbrane filters $(0.45 \mu \mathrm{m}$ pore size, Gelman Instrument Co.). Each filter was washed immediately in $10 \mathrm{ml} \mathrm{ME}$ medium (without glucose) containing unlabelled purine base or nucleoside $\left(50 \mu \mathrm{g} \mathrm{ml}^{-1}\right)$. Filters were dried and their radioactivities were determined in a Packard Tri-Carb scintillation counter.

\section{RESULTS}

\section{Isolation of mutants}

Cells were harvested by centrifugation from a $5 \mathrm{ml}$ overnight nutrient broth culture of a Salmonella typhimurium purine auxotroph (strain SL751), washed once with $0.1 \mathrm{M}$-citrate buffer $\mathrm{pH} 5.5$ and resuspended in $5 \mathrm{ml}$ of the same buffer containing $150 \mu \mathrm{g} \mathrm{NG} \mathrm{ml}^{-1}$. The bacterial suspension was incubated for $1 \mathrm{~h}$ in a stationary water-bath at $37^{\circ} \mathrm{C}$. The cells were then collected by centrifugation, washed once with $0 \cdot 1 \mathrm{M}$-phosphate buffer $\mathrm{pH} 7.4$ and suspended in $100 \mathrm{ml} \mathrm{ME}$ supplemented with casein hydrolysate $(0.1 \%)$, uridine and guanine (each at $20 \mu \mathrm{g} \mathrm{ml}^{-1}$ final concentration). The flask was incubated in a rotary shaker waterbath for $4 \mathrm{~h}$ at $37^{\circ} \mathrm{C}$, then ampicillin $\left(40 \mu \mathrm{g} \mathrm{ml}^{-1}\right)$ was added to the culture and incubation was continued overnight at $37^{\circ} \mathrm{C}$ with agitation. The cells were collected by centrifugation, washed four times with prewarmed $0.85 \%$ (w/v) $\mathrm{NaCl}$ and the entire cell pellet was plated on four ME/glucose plates supplemented with $2 \mu \mathrm{g}$ hypoxanthine $\mathrm{ml}^{-1}$ and $40 \mu \mathrm{g}$ guanine $\mathrm{ml}^{-1}$. Mutants defective in guanine uptake or metabolism would appear as small colonies on this medium as their growth would be dependent on the hypoxanthine concentration. One mutant, designated CB-3, was selected for growth studies in defined liquid media to compare its phenotypic growth pattern with that of the parent strain. The generation time of mutant CB-3 with guanine or xanthine was four to five times higher than that of the parent (168 compared with $42 \mathrm{~min}$ ), consistent with a defective guanine-xanthine phosphoribosyltransferase (GPRT) phenotype (Gots et al., 1972).

A second mutant (GP103) with a defective GPRT phenotype was isolated from S. typhimurium strain TM445. As indicated in Table 1, strain TM445 has a double block (purI and purC) in the de novo biosynthesis of purines, is hypoxanthine (H)PRT deficient ( hpt) and cannot convert GMP to IMP $(g u a C)$. The purine requirement may be satisfied with adenine via adenine (A)PRT or hypoxanthine via GPRT (Chou \& Martin, 1972). When strain TM445 was plated on ME/glucose agar supplemented with casein hydrolysate and hypoxanthine, a zone of inhibition occurred around a paper disc saturated with guanine or xanthine. The inhibition is the result of competition between the natural substrate and hypoxanthine for GPRT. Colonies occasionally appeared within this zone of inhibition and one (designated GP103) was isolated for further characterization. Possible reversion to $\mathrm{guaC}^{+}$was ruled out by confirming the absence of GMP reductase. Mutant GP103 had a generation time two- to fourfold greater than that of its parent, TM445, when grown on a defined medium supplemented with xanthine and hypoxanthine (each $20 \mu \mathrm{g} \mathrm{ml}^{-1}$ ). These phenotypic characteristics may represent a change in substrate specificity of GPRT analogous to a previously described mutation in HPRT (Benson \& Gots, 1975; Berlin \& Oliver, 1975) or an altered purine uptake mechanism. The generation time of each mutant when grown in a hypoxanthine-supplemented medium was comparable with that of its respective parent strain. Thus, the phenotype relative to hypoxanthine uptake and metabolism appeared to be unaltered. 
Table 2. Purine phosphoribosyltransferase activities

In all cases there were no significant differences in PRT activities with adenine (results not shown).

\begin{tabular}{|c|c|c|c|c|}
\hline \multirow[b]{2}{*}{ Strain } & \multirow[b]{2}{*}{ Relevant genotype } & \multicolumn{3}{|c|}{ PRT activity (nmol nucleotide formed $\mathrm{min}^{-1}$ ) } \\
\hline & & Guanine & Hypoxanthine & Xanthine \\
\hline LT-2 & & $18 \cdot 2$ & $28 \cdot 0$ & $24 \cdot 1$ \\
\hline $\mathrm{AB} 47$ & gpt & $0 \cdot 18$ & $21 \cdot 2$ & 0.36 \\
\hline SL751 & & $23 \cdot 2$ & $25 \cdot 8$ & ND \\
\hline CB-3 & guaP & $18 \cdot 1$ & $37 \cdot 9$ & 31.9 \\
\hline $\mathrm{CB}-3 / \mathrm{F}^{\prime} 128^{*}$ & guaP/gpt $t^{+}$ & $32 \cdot 3$ & $33 \cdot 4$ & $31 \cdot 2$ \\
\hline TM445 & hpt & $17 \cdot 6$ & $10 \cdot 2$ & $27 \cdot 2$ \\
\hline GP103 & hpt Xar & $12 \cdot 9$ & $10 \cdot 4$ & $24 \cdot 7$ \\
\hline
\end{tabular}

ND, Not determined.

* $F^{\prime} 128$ is an $F^{\prime}$ episome carrying pro $^{+} g p t^{+}$(Low, 1972).

Table 3. Uptake of guanine and guanosine

Uptake was measured as described in Methods. The lower activities of the parent strain, SL751, compared with the prototroph were reproducible. All values were derived from the calculated uptake of ${ }^{14} \mathrm{C}$-labelled purine in $2 \mathrm{~min}$; uptake was linear with time during this period. The results are expressed as a percentage of the uptake by the wild-type control, which was 400 pmol guanine $(2 \mathrm{~min})^{-1}$ and $488 \mathrm{pmol}$ guanosine $(2 \mathrm{~min})^{-1}$.

\begin{tabular}{lcc} 
& \multicolumn{2}{c}{ Uptake (\% of control) } \\
\cline { 2 - 3 } Strain & Guanine & Guanosine \\
LT-2 & 100 & 100 \\
AB47 & 18 & 25 \\
SL751 & 73 & 81 \\
CB-3 & 34 & 39 \\
CB-3/F'128 & 46 & 56
\end{tabular}

\section{Phosphoribosyltransferase studies}

The phenotype of mutants CB-3 and GP103 could be explained by alterations in the respective PRT activities; however, no differences were found between parent and mutant in either case (Table 2). Genetic complementation of the GPRT gene ( $g p t$ ) in CB-3 by the $\mathrm{F}^{\prime} 128$ episome $\left(\mathrm{pro}^{+} \mathrm{gpt}^{+}\right)$resulted in the expected gene dosage effect on GPRT activities, but did not improve the growth of the mutant on guanine. The PRT activities for all purine substrates were comparable between the two mutants (CB-3 and GP103) and their respective parent strains (SL751 and TM445). Thus, the different growth phenotypes were independent of the PRT activities, leading to the consideration that the substrate specificity of GPRT had been altered toward a greater affinity for hypoxanthine than guanine or xanthine. This possibility was easily investigated with strains TM445 and GP103 since HPRT was absent and a substrate competition of GPRT for hypoxanthine and xanthine could be measured with crude cell-free extracts. In both instances, the conversion of ${ }^{14} \mathrm{C}$-labelled hypoxanthine to IMP was significantly inhibited by the unlabelled xanthine, while conversion of xanthine to XMP was unaffected by hypoxanthine. Thus, the substrate specificity of GPRT in GP103 was similar to the parental strain.

\section{Uptake of purine bases and nucleosides}

An alternative explanation of the mutant phenotypes implicated a specific purine transport system in bacteria. The uptake of ${ }^{14} \mathrm{C}$-labelled purine bases and nucleosides was investigated using intact, resting cells of the mutant strain CB-3 and its parent SL751 (Table 3). The parent strain SL751 was less active in the uptake of guanine and guanosine than the original prototrophic strain, LT-2. This could indicate a membrane or transport 
Table 4. Competitive uptake studies

Uptake was determined as described in Methods. Competition was measured by adding unlabelled purine $\left(0 \cdot 1 \mu \mathrm{mol} \mathrm{ml}^{-1}\right)$ with the labelled substrate. Results in parentheses show the uptake as a percentage of that in the control without addition.

\begin{tabular}{|c|c|}
\hline $\begin{array}{c}{ }^{14} \mathrm{C} \text {-labelled } \\
\text { substrate }\end{array}$ & $\begin{array}{l}\text { Unlabelled } \\
\text { addition }\end{array}$ \\
\hline Hypoxanthine & None \\
\hline Hypoxanthine & Xanthine \\
\hline Xanthine & None \\
\hline Xanthine & Hypoxanthine \\
\hline
\end{tabular}

\begin{tabular}{|c|c|}
\hline \multicolumn{2}{|c|}{ Uptake $\left[\mathrm{pmol}(2 \mathrm{~min})^{-1}\right]$} \\
\hline Strain TM445 & Strain GP103 \\
\hline $\begin{array}{l}236 \\
76(32 \%) \\
113 \\
145(128 \%)\end{array}$ & $\begin{array}{l}217 \\
209(96 \%) \\
62 \\
39(63 \%)\end{array}$ \\
\hline
\end{tabular}

Table 5. Cotransduction frequencies

Transductions were performed as described in Methods. Cotransduction frequency is measured as the percentage of unselected marker scored among the selected transductants. The actual numbers of colonies examined are shown in parentheses.

$\begin{array}{lcccc}\text { Donor } & \text { Recipient } & \begin{array}{c}\text { Selected } \\ \text { marker }\end{array} & \begin{array}{c}\text { Unselected } \\ \text { marker }\end{array} & \begin{array}{c}\text { Cotransduction } \\ (\%)\end{array} \\ \text { CB-3 } & \text { JF12 } & \text { nadC } & \text { guaP } & 48(21 / 43) \\ 0002 & \text { CB-3 } & \text { guaP+ } & \text { gziA } & 28(14 / 50) \\ \text { PM553 } & \text { CB-3 } & \text { guaP+ } & \text { leu } & <2(0 / 50) \\ \text { SM16 } & \text { CB-3 } & \text { guaP } & \text { ace } & <1(0 / 100) \\ \text { Pan5 } & \text { CB-3 } & \text { guaP } & \text { pan } & <2(0 / 50) \\ \text { KP4065 } & \text { CB-3 } & \text { guaP } & \text { deoD } & <2(0 / 50)\end{array}$

defect which lowered the rate of purine uptake. This postulated defect apparently does not cause a significant change in the growth of the strain as determined by generation time measurements. However, mutant CB-3 was $50 \%$ less active than strain SL751 in guanine and guanosine uptake and showed only one-third of the original wild-type activity. Although GPRT is important in the uptake of both guanine and guanosine, as shown by the results obtained with the $g p t$ strain (AB47), the $g p t$ merodiploids of $\mathrm{CB}-3 / \mathrm{F}^{\prime} 128$ were still transport deficient. Thus, the defective uptake in CB-3 appears to be genetically distinct from gpt.

Analogous studies, performed with mutant strain GP103 and its parent TM445 indicated that both strains efficiently take up hypoxanthine and xanthine. However, in competitive uptake studies (Table 4), GP103 showed a reversal of the parental uptake specificity. The uptake of $\left[{ }^{14} \mathrm{C}\right]$ hypoxanthine, normally inhibited by unlabelled xanthine, was unaffected by xanthine addition. Unlabelled hypoxanthine had no effect on $\left[{ }^{14} \mathrm{C}\right]$ xanthine uptake by TM445, but inhibited the uptake of xanthine by strain GP103. This reversal in the uptake specificities may explain the ability of strain GP103 to continue utilizing hypoxanthine for growth in the presence of xanthine.

\section{Mapping the genetic lesion in mutant $\mathrm{CB}-3$}

The phenotypic characteristic of strain CB-3 is poor growth on guanine (generation time three- to fourfold longer than for strain SL751), apparently due to a defect in a purine transport system. This transport defect is independent of the GPRT gene since PRT activity is normal in CB-3, and the $\mathrm{F}^{\prime} 128$ episome, which carries the $g p t^{+}$gene, increases PRT activity for guanine without altering the transport deficiency. These two findings imply a genetic lesion in mutant CB-3 distinct from gpt. We designate this guanine-xanthine uptake defect as resulting from a mutation in the gene guaP. Conjugational studies with a series of Salmonella $\mathrm{Hfr}$ strains indicated a linkage of the GuaP phenotype with ilv and pro. A gradient of transmission model was constructed from results obtained in crosses with donor strains SA464 and SA955 (Sanderson et al., 1972) placing guaP between 0 and 5 min 


\section{Table 6. Uptake of $\left[{ }^{14} \mathrm{C}\right]$ guanine by E. coli strains}

Uptake of $\left[{ }^{14} \mathrm{C}\right]$ guanine was determined over a 2 min period as described in Methods. Results are expressed as a percentage of the uptake by a prototrophic $E$. coli $\mathrm{K}-12$ control strain, which was $600 \mathrm{pmol}(2 \mathrm{~min})^{-1}$. Ace ${ }^{+} \mathrm{Nad}^{+}$transductants, obtained by P1 transduction of the designated mutants, were also tested.

\begin{tabular}{ccc} 
& \multicolumn{2}{c}{ Uptake (\% of control) } \\
\cline { 2 - 3 } Strain designation & $\begin{array}{c}\text { Mutant } \\
\text { Ace+ } \text { Nad }^{+} \text {transductant }\end{array}$ \\
H $\Delta 10$ & $98 \cdot 5$ & \\
K $\Delta 22$ & $28 \cdot 7$ & $97 \cdot 4$ \\
K $\Delta 17$ & $15 \cdot 0$ & $59 \cdot 0$ \\
K $\Delta 27$ & $15 \cdot 0$ &
\end{tabular}

on the Salmonella chromosome. Cotransduction studies (Table 5) with known genes in this region (Sanderson \& Hartman, 1978) indicate the order, azi-guaP-nadC.

\section{Detection and mapping of guaP in Escherichia coli}

Langley and Guest (1977) isolated a series of deletion mutants in their studies of geneenzyme relationships of 2-oxo-acid dehydrogenase in $E$. coli. The deletions in several of these mutants encompassed the region proposed by us to include the guaP locus. J. R. Guest generously supplied us with representative strains which we examined for the GuaP phenotype (Table 6). All strains except $\mathrm{H} \Delta 10$ were deficient in guanine uptake and hence include guaP in their deletion. The deletion was corrected in two of these strains $(\mathrm{K} \Delta 22$ and $\mathrm{H} \Delta 3$ ) by P1 transduction with simultaneous selection for $\mathrm{Nad}^{+}$and Ace ${ }^{+}$. These derivatives showed partial to full restoration of guanine uptake activity (Table 6). These results, in comparison with the proposed lengths of the deletion mutations (Langley \& Guest, 1977, 1978), are consistent with the proposed order aziA-guaP-nadC.

\section{DISCUSSION}

We have described two mutants of $S$. typhimurium with alterations in guanine uptake. These lesions appear to be distinct and separate from the specific purine phosphoribosyltransferases. The poor growth of strain CB-3 on guanine and xanthine mimics a PRT phenotype (Gots et al., 1972) yet its PRT activities are unaltered and the defective uptake phenotype is not corrected when a plasmid carrying $g p t^{+}$is introduced. We have designated this defective guanine uptake phenotype GuaP. This provides genetic evidence that purine transport is mediated by a specific moiety separate from PRT. Burton (1977) suggested that uptake of purines is mediated by a transport system and that uptake is facilitated if the intracellular base is removed by a PRT. Our model completes this interpretation and extends the data by indicating a specificity in the transport system and the purine to be transported. The second mutant, GP103, could possess an altered carrier protein. The specificity of the uptake defect implies that at least one, and perhaps two or more, carrier proteins might be present for adenine and hypoxanthine. We propose, therefore, that the carrier protein has an integral association with the inner membrane of the cell, and functions as the initial recognition and entrance site for specific purine bases. Thus, purine metabolism could be altered via a change in the transport system or in the ribosylphosphorylation system (Berlin \& Stadtman, 1966). This paper presents data to support this conclusion. The location of the guaP lesion was determined by the construction of a conjugational gradient of transmission graph and then pinpointed by cotransduction analysis. Studies with the deletion mutants of Langley \& Guest (1977) indicated that the purine uptake mechanism is also present in $E$. coli and provided additional genetic data to confirm the gene sequence aziA-guaP-nadC. 
Major questions remain concerning purine uptake, the nature of the carrier or transport system and the specificity of the system. While genetic and biochemical studies (Gots et al., 1972; Hochstadt-Ozer \& Stadtman, $1971 b$; Roy-Burman \& Visser, 1975) have distinguished three PRTs in enteric bacteria (guanine-xanthine, hypoxanthine and adenine PRT) this paper presents the first genetic evidence of a specific purine transport system. Specific transport of guanine was first described by Thakar \& Kalle (1968). Further study of purine transport should include the isolation of adenine and hypoxanthine transport-deficient strains.

This investigation was supported by grant no. 02790 awarded by the National Cancer Institute, DHEW, and by grant PCM 02235 from the National Science Foundation. C.E. B. was a Penn Plan Scholar.

\section{REFERENCES}

Alford, B. L. \& Barnes, E. M. (1976). Hypoxanthine transport by cultured chinese hamster lung fibroblasts. Journal of Biological Chemistry 251, 4823-4827.

Benson, C. E. \& Gors, J.S. (1975). Genetic modification of substrate specificity of hypoxanthine phosphoribosyltransferase in Salmonella typhimurium. Journal of Bacteriology 121, 77-82.

Benson, C. E., Brehmeyer, B. A. \& Gots, J. S. (1971). Requirement of cyclic AMP for induction of GMP reductase in Escherichia coli. Biochemical and Biophysical Research Communications 43, 1089-1094.

Berlin, R. D. (1970). Specificities of transport systems and enzymes. Science 168, 1539-1545.

Berlin, R. D. \& Oliver, J. M. (1975). Membrane transport of purine and pyrimidine bases and nucleosides in animal cells. International Review of Cytology 42, 287-336.

Berlin, R. D. \& Stadtman, E. R. (1966). A possible role of purine nucleotide pyrophosphorylases in the regulation of purine uptake by Bacillus subtilis. Journal of Biological Chemistry 241, 2679-2686.

Burton, K. (1977). Transport of adenine, hypoxanthine and uracil into Escherichia coli. Biochemical Journal 168, 195-204.

Chou, J. Y. \& Martin, R. G. (1972). Purine phosphoribosyltransferases of Salmonella typhimurium. Journal of Bacteriology 112, 1010-1013.

Ely, B., Weppelman, R. M., Massey, JR, H. C. \& Hartman, P. E. (1974). Some improved methods in P22 transduction. Genetics 76, 625-631.

Fosier, J. W. \& MOAT, A. G. (1978). Mapping and characterization of the nad genes in Salmonella typhimurium LT-2. Journal of Bacteriology 133, 775-779.

Gots, J. S., Benson, C. E. \& Shumas, S. R. (1972). Genetic separation of hypoxanthine and guaninexanthine phosphoribosyltransferase activities by deletion mutations in Salmonella typhimurium. Journal of Bacteriology 112, 910-916.

Hochstadt-Ozer, J. \& Stadtman, E. R. (1971a). The regulation of purine utilization in bacteria. II. Adenine phosphoribosyltransferase in isolated membrane preparations and its role in transport of adenine across the membrane. Journal of Biological Chemistry 246, 5304-5311.
Hochstadt-Ozer, J. \& Stadtman, E. R. (1971 b). The regulation of purine utilization in bacteria. III. The involvement of purine phosphoribosyltransferases in the uptake of adenine and other nucleic acid precursors by intact resting cells. Journal of Biological Chemistry 246, 5312-5320.

JACKMAN, L. E. \& HochSTADT, J. (1976). Regulation of purine utilization in bacteria. IV. Characterjzation of hypoxanthine and guanine uptake into isolated membrane vesicles from Salmonella typhimurium. Journal of Bacteriology 126, 312326.

LANGLey, D. \& GuesT, J. R. (1974). Biochemical and genetic characteristics of deletion and other mutant strains of Salmonella typhimurium LT2 lacking $\alpha$-keto acid dehydrogenase complex activities. Journal of General Microbiology 82, 319-335.

Langley, D. \& Guest, J. R. (1977). Biochemical genetics of the $\alpha$-keto acid dehydrogenase complexes in Escherichia coli $\mathrm{K} 12$ : isolation and biochemical properties of deletion mutants. Journal of General Microbiology 99, 263-276.

LANGLEY, D. \& Guest, J. R. (1978). Biochemical genetics of the $\alpha$-keto acid dehydrogenase complexes of Escherichia coli K12: genetic characterization and regulatory properties of deletion mutants. Journal of General Microbiology 106, 103-117.

Low, K. B. (1972). Escherichia coli K12 F-prime factors, old and new. Bacteriological Reviews 36, 587-607.

Pickering, W. R. \& Woods, R. A. (1972). The uptake and incorporation of purines by wild-type Saccharomyces cerevisiae and a mutant resistant to 4-aminopyrazolo(3,4-d)pyrimidine. Biochimica et biophysica acta 264, 45-58.

RosNer, J. L. (1972). Formation, induction and curing of bacteriophage P1 lysogens. Virology 49, 679-689.

Roy-BurmaN, S. \& VISSER, D. W. (1975). Transport of purines and deoxyadenosine in Escherichia coli Journal of Biological Chemistry 250, 9270-9275.

Sanderson, K. E. \& Hartman, P. E. (1978). Linkage map of Salmonella typhimurium, edition V. Microbiological Reviews 42, 471-519. 
Sanderson, K. E., Ross, H., Ziegler, L. \& MAKELA, P. H. (1972). $\mathrm{F}^{+}, \mathrm{Hfr}$ and $\mathrm{F}^{\prime}$ strains of Salmonella typhimurium and Salmonella abony. Bacteriological Reviews 36, 608-637.

Thakar, J. H. \& Kalle, G. P. (1968). Defective guanine uptake in an 8-azaguanine-resistant mutant of Salmonella typhimurium. Journal of Bacteriology 95, 458-464.

VOGEL, H. J. \& BONNER, D. M. (1956). Acetylorni- thinase of Escherichia coli: partial purification and some properties. Journal of Biological Chemistry 218, 97-106.

ZylKa, J. M. \& PlagemanN, P. G. W. (1975). Purine and pyrimidine transport by cultured Novikoff cells: specificities and mechanism of transport and relationship to phosphoribosylation. Journal of Biological Chemistry 250, 5756-5767. 